\title{
Analysis of Electric Vehicles Motion Modes Influence on Traction Batteries Aging Based on WLTC
}

\author{
Nikolay I. Shchurov*a, Alexander A. Shtanga, \\ Sergei I. Dedova and Wu Xiaogang ${ }^{b}$ \\ ${ }^{a}$ Novosibirsk State Technical University \\ Novosibirsk, Russian Federation \\ ${ }^{b}$ Harbin University of Science and Technology \\ Harbin, China
}

Received 29.11.2020, received in revised form 01.12.2020, accepted 03.12.2020

Abstract. The paper considers the growth rates of electric vehicles, taking into account the development of electrochemical energy storage. The main lithium batteries aging mechanisms under conditions of uneven load and reversible nature of energy exchange processes with short modes of recharging batteries during regenerative braking are determined. To assess the aging of the lithium battery, the WLTC driving cycle was taken as a basis, in accordance with which the load on the electric vehicle energy storage unit the was formed. A Nissan Leaf equipped with energy storage units (ESU) of different energy intensity was adopted as a test sample. Current diagrams were obtained for one battery cell, minimum, average and maximum currents, as well as durations of traction, braking and stopping modes in various control modes of electric rolling stock are given. An assumption is made about the growth of the energy intensity of the ESU in the future period and its influence on the load of the storage battery is determined. On the basis of the data processing carried out, the main changes in the processes occurring in the power source, associated with an increase in the energy intensity of the ESU, have been revealed.

Keywords: electric transport, electrochemical energy storage, lithium battery, driving cycles, energy recovery.

Citation: Shchurov N.I., Shtang A.A., Dedov S.I., Xiaogang Wu. Analysis of Electric vehicles motion modes influence on traction batteries aging based on WLTC, J. Sib. Fed. Univ. Eng. \& Technol., 2020, 13(8), 977-990. DOI: 10.17516/1999494X-0279

(C) Siberian Federal University. All rights reserved

This work is licensed under a Creative Commons Attribution-Non Commercial 4.0 International License (CC BY-NC 4.0).

* Corresponding author E-mail address: nischurov@mail.ru 


\title{
Анализ влияния режимов движения электромобилей на процесс старения тяговых аккумуляторов на основе цикла WLTC
}

\author{
Н.И. Щуров ${ }^{\text {a }, ~ А . А . ~ Ш т а н г, ~}$ \\ С.И. Дедов ${ }^{\text {, }}$ У Сяоган \\ ${ }^{a}$ Новосибирский государственный технический университет \\ Российккая Федерациия, Новосибирск

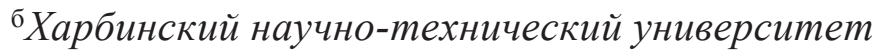 \\ Китай, Харбин
}

Аннотация. В работе рассмотрены темпы роста электротранспортных средств с учетом развития электрохимических накопителей энергии. Определены основные механизмы старения литиевых аккумуляторов в условиях неравномерной нагрузки и с учетом реверсивного характера процессов энергообмена с короткими режимами подзаряда аккумуляторов при рекуперативном торможении. Для оценки старения литиевого аккумулятора за основу принят ездовой цикл WLTC, в соответствии с которым формировалась нагрузка на блок накопителей электромобиля. В качестве исследуемого образца принят Nissan Leaf, оснащенный различными по энергоемкости блоками накопителей (БН). Получены для одной аккумуляторной ячейки токовые диаграммы, приведены минимальные, средние и максимальные токи, а также длительности режимов тяги, торможения и остановки в различных режимах управления электроподвижного состава. Сделано предположение о росте энергоемкости БН в будущем периоде и определено ее влияние на нагрузку аккумуляторной батареи (АБ). На основе проведенной обработки данных выявлены основные изменения в протекающих в энергоустановке процессах, связанные с увеличением энергоемкости БН.

Ключевые слова: электротранспорт, электрохимические накопители энергии, литиевый аккумулятор, ездовые циклы, рекуперация энергии.

Цитирование: Щуров, Н.И. Анализ влияния режимов движения электромобилей на процесс старения тяговых аккумуляторов на основе цикла WLTC / Н.И. Щуров, А.А. Штанг, С.И. Дедов, У Сяоган // Журн. Сиб. федер. ун-та. Техника и технологии, 2020. 13(8). С. 977-990. DOI: 10.17516/1999-494X-0279

\section{Введение}

Современные тенденции развития автомобильной индустрии направлены на увеличение выпуска транспортных средств, оснащенных гибридной или полностью электрической энергоустановкой. Согласно аналитическому прогнозу Bloomberg New Energy Finance (BNEF), производство электромобилей в период с 2020 по 2025 г. будет возрастать в среднем на 30 \% ежегодно, а темп распространения электротранспортных средств будет близок к экспоненциальному до 2030 г. (рис. 1) [1]. Существенный рост в первую очередь обусловлен снижением стоимости блока накопителей (БН) электрической энергии, как правило, представленного модулями, собранными из отдельных литиевых аккумуляторов (ячеек). В настоящее время БН определяет значительную часть стоимости электромобиля и составляет $30 \ldots 45 \%$ [2]. Поэтому удешевление БН существенно повлияет на доступность применения электрокаров, а техническое совершенствование накопителей приведет к увеличению запаса автономного хода и повышению динамических показателей электротранспортных средств (ЭТС). 
На рис. 2 изображено прогнозируемое изменение стоимости $\kappa B m \cdot ч$ литиевых аккумуляторов. Исходя из прогноза, цена будет падать до 2030 г., дальнейшее увеличение темпов производства и оптимизации технологических процессов не будет давать значительного эффекта. При этом в докладе BNEF отмечается, что до 2030 г. аккумуляторы на основе лития останутся основным типом, используемым на электротранспорте [1].

Ключевым является вопрос режимов эксплуатации, определяющих время жизни АБ. Именно он на данном этапе во многом ограничивает ресурс электромобиля. Для увеличения времени жизни АБ предпочтительны режимы с равномерной нагрузкой и зарядом [3]. Однако при их использовании в транспортном комплексе динамика движения неравномерна и определяется дорожными условиями, а нагрузка на БН изменяется в широких пределах. Так, в момент интенсивного разгона ток кратковременно может многократно превосходить среднечасовой [4]. Дополнительным фактором, ограничивающим ресурс и требующим углубленного изучения, служит динамический режим частого энергообмена с короткими циклами реверса в режиме рекуперации при электрическом торможении.

Важность выявления механизмов старения АБ требует проведения масштабных исследований в данной области. Так, в работах Pankaj Arora и др. [5] обозначены механизмы старения

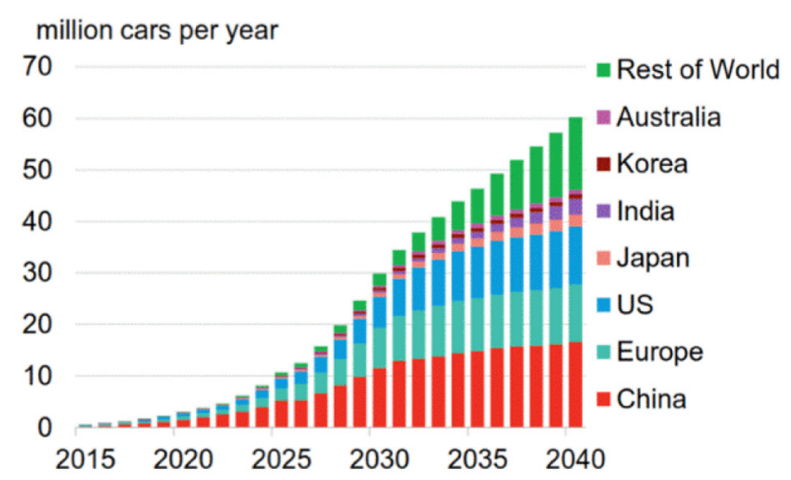

Рис. 1. График ежегодных и прогнозных продаж электрокаров в мире

Fig. 1. Annual and projected sales of electric cars in the world

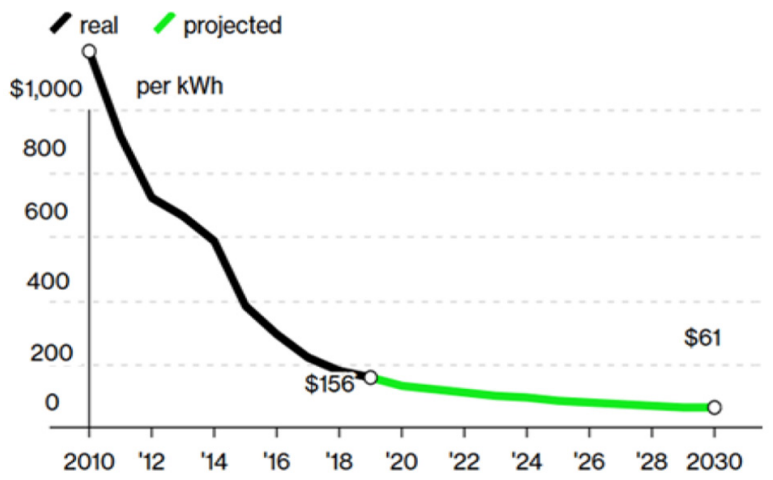

Рис. 2. Изменение цены и прогнозная стоимость Li-ion аккумуляторов в $\kappa B m \cdot \varphi$

Fig. 2. Change in price and forecasted cost of Li-ion batteries per $\mathrm{kWh}$

$$
-979-
$$


литий-ионных аккумуляторов - заряд сверх номинала (Overcharge Phenomena), процессы разложения и восстановления электролитов (Electrolyte Decomposition Processes), процесс саморазряда (Self-discharge Processes), разложение положительного электрода (Positive Electrode Dissolution).

В работе Daniel-Ioan Stroe и др. [6] рассмотрено ускоренное старение БН на базе литийникель-марганец-кобальд-оксидных аккумуляторов (NMC) электромобиля при движении согласно циклу WLTC. Согласно полученным результатам, для рассматриваемого профиля движения внутреннее сопротивление АБ возрастает в 3 раза через 3 года эксплуатации, а за 5,8 лет происходит снижение мощности на $20 \%$. Однако в работе Samveg Saxena и др. [7] по определению срока службы АБ на основе требуемой динамики при движении ЭТС показано, что БН электромобилей удовлетворяют потребностям в перевозке даже после потери $20 \%$ от своей изначальной энергоемкости, а срок службы АБ можно продлить с помощью уменьшения глубины разряда батареи и более частой подзарядки ее на зарядных станциях.

Механизм старения литиевых аккумуляторов при использовании их в составе тяговой энергоустановки электромобиля изучен недостаточно. Важным остается вопрос влияния на срок службы аккумуляторов таких факторов, как:

- высокие токи заряда и разряда;

- $\quad$ реверс тока, возникающий при чередовании пуска и торможения;

- скорость нарастания и спада тока нагрузки и заряда.

Целью исследования является анализ факторов, влияющих на деградацию материалов аккумуляторной батареи в составе энергетической установки ЭТС с учетом тенденции, направленной на увеличение энергоемкости БН. В качестве нагрузочного цикла использован всемирный ездовой цикл для легкового транспорта WLTC class 3, так как он в настоящее время выступает общепринятым стандартом. Для исследования современных моделей ЭТС принят один из наиболее распространенных электромобилей марки Nissan Leaf с АБ энергоемкостью 24 и 62 кBm·ч.

В работе проводится анализ цикла WLTC с позиции возникающих токов нагрузки аккумуляторной батареи Nissan Leaf различной энергоемкости. Оцениваются пиковые нагрузки в режимах тяги и торможения, средние значения в фазах цикла, количество реверсов потока мощности и изменения параметров с учетом тенденции увеличения энергоемкости БН.

В первом разделе проведен анализ цикла WLTC, а именно оценка режимов движения в разных фазах цикла, их относительные доли, средняя длительность и т.д. Во втором разделе осуществлено приведение скоростной характеристики WLTC к диаграммам тока в аккумуляторной ячейке при разных энергоемкостях БН. В третьем разделе проведена статистическая обработка токового ряда с разделением на фазы цикла WLTC, получены спектрограммы токов при электрическом торможении и тяге. В четвертом разделе представлены выводы по результатам обработки данных.

\section{1. Анализ цикла WLTC}

Всемирный цикл испытаний легковых автомобилей (WLTC) - современный стандарт ездового цикла, являющийся частью процедуры WLTP по определению расходов топлива и электроэнергии автомобилей и электромобилей (рис. 3). Он создан на основе статистических

$$
-980-
$$




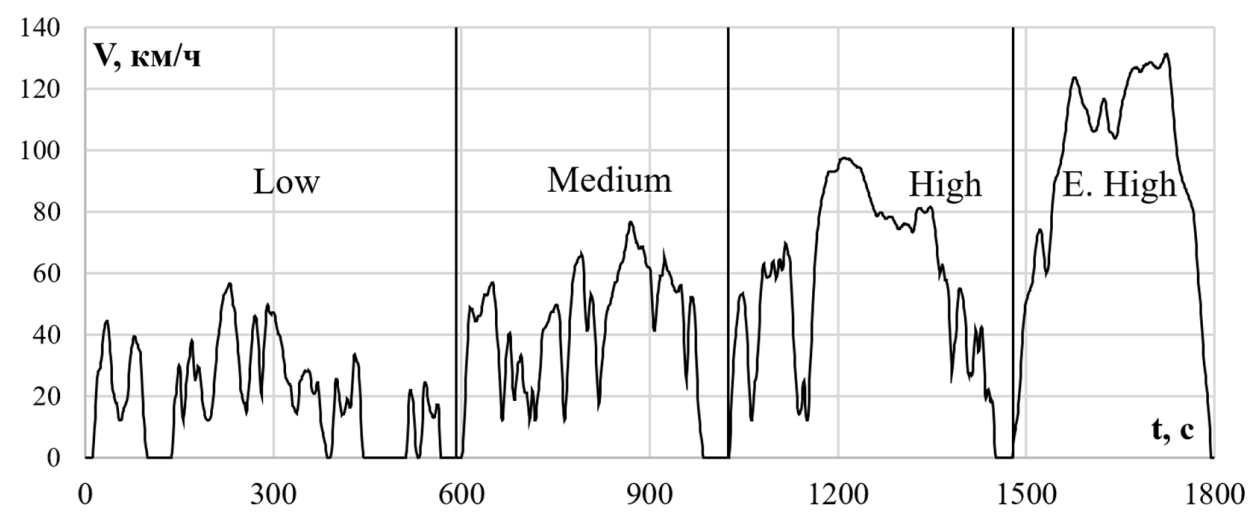

Рис. 3. Цикл WLTC

Fig. 3. WLTC diagram
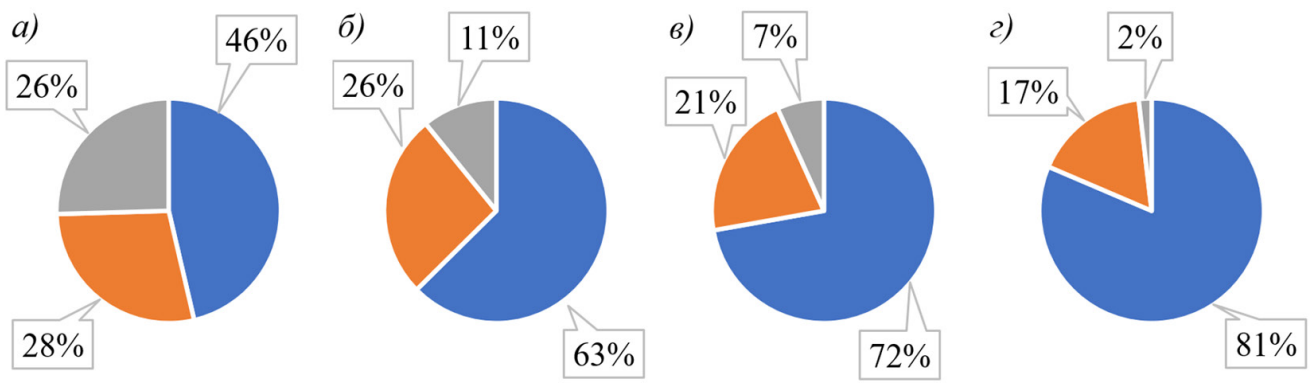

• Тяга " Торможение Остановка

Рис. 4. Диаграммы соотношений долей времени в различных режимах движения за цикл: a - Low; б Medium; в - High; г - Extra High

Fig. 4. Diagrams of the proportions of time shares in different driving modes per cycle: a - Low; 6 - Medium; в - High; г-Extra High

данных режимов движения легкового транспорта в разных странах. Цикл представляет собой четыре участка с разными режимами управления ЭТС, первые два из которых (Low и Medium) имитируют движение транспорта в городской среде, а следующие два (High и Extra High) - загородный режим движения.

На рис. 4 приведены диаграммы долей времени тяги, торможения и остановки. Так, наименее динамичным является режим управления - Low с соотношением долей времени: 46 \% тяга; $26 \%$ - выбег; 28 \% - торможение, а наиболее динамичным режимом управления - Extra high с минимальной долей остановки и торможения в $2 \%$ от общего времени режима.

В табл. 1 представлено количество актов тяги, торможения и остановки в фазах цикла WLTC, а в табл. 2 - средняя длительность этапов.

Таким образом, фаза Low представляет собой частое чередование коротких режимов тяги и торможения, а фаза Extra High - длительный режим тяги с разгоном до высоких скоростей с последующим резким торможением. В табл. 3 приведена минимальная, средняя и максимальная длительность режима тяги, торможения и остановки. 
Таблица 1. Количество режимов тяги, торможения и остановки

Table 1. Number of tractions, brakes and stops

\begin{tabular}{|c|c|c|c|c|}
\hline \multirow{2}{*}{ Скоростной режим } & \multicolumn{3}{|c|}{ Количество повторений режимов } & \multirow{2}{*}{$\begin{array}{c}\text { Длительность } \\
\text { режима } \\
\text { управления, с }\end{array}$} \\
\hline & Тяга & Торможение & Остановка & \\
\hline Low & 33 & 32 & 5 & 589 \\
\hline Medium & 17 & 17 & 1 & 433 \\
\hline High & 15 & 15 & 2 & 455 \\
\hline E. high & 4 & 4 & 1 & 323 \\
\hline
\end{tabular}

Таблица 2. Длительность режимов тяги, торможения и остановки

Table 2. Duration of traction, braking and stopping modes

\begin{tabular}{|c|c|c|c|}
\hline \multicolumn{3}{|c|}{ Математическое ожидание длительности режима } \\
\hline Скоростной режим & Тяга, с & Торможение, $\mathrm{c}$ & Остановка, с \\
\hline Low & 8,55 & 5,09 & 28,8 \\
\hline Medium & 16,29 & 6,41 & 47 \\
\hline High & 22,47 & 5,93 & 6 \\
\hline E. high & 66,25 & 13 & 6,5 \\
\hline
\end{tabular}

Таблица 3. Минимальная, максимальная и средняя длительность режимов

Table 3. Minimum, maximum and average duration of modes

\begin{tabular}{|c|c|c|c|c|c|c|c|c|c|}
\hline \multirow{2}{*}{$\begin{array}{c}\text { Скоростной } \\
\text { режим }\end{array}$} & \multicolumn{4}{|c|}{ Тяга, с } & \multicolumn{3}{c|}{ Торможение, с } & \multicolumn{3}{c|}{ Остановка, с } \\
\cline { 2 - 11 } & $\mathrm{T}_{\min }$ & $\mathrm{T}_{\mathrm{cp}}$ & $\mathrm{T}_{\max }$ & $\mathrm{T}_{\min }$ & $\mathrm{T}_{\mathrm{cp}}$ & $\mathrm{T}_{\max }$ & $\mathrm{T}_{\min }$ & $\mathrm{T}_{\mathrm{cp}}$ & $\mathrm{T}_{\max }$ \\
\hline Low & 1 & 8,55 & 40 & 1 & 5,09 & 15 & 2 & 24,2 & 66 \\
\hline Medium & 3 & 16,29 & 56 & 2 & 6,41 & 17 & 33 & 33 & 33 \\
\hline High & 3 & 22,47 & 201 & 1 & 5,93 & 14 & 26 & 33 & 40 \\
\hline E. high & 24 & 66,25 & 98 & 3 & 13,00 & 29 & 6 & 6 & 6 \\
\hline
\end{tabular}

\section{2. Расчет нагрузки АБ}

В соответствии с принятым в качестве исследуемого образца ЭТС Nissan Leaf в табл. 4 отражены основные параметры, необходимые для построения модели.

В статье используется метод расчета, представленный на рис. 5.

В блок-схеме (рис. 5) приняты следующие обозначения: $F_{m}$ и $B_{m}-$ соответственно, сила, реализуемая двигателем в режиме тяги и торможения $(H) ; F_{t}$ - полное сопротивление транспортного средства, которое состоит из сопротивления качению $\left(F_{f}\right)$, сопротивления воздуха $\left(F_{w}\right)$, сопротивления уклона $\left(F_{i}\right)$ и сопротивления ускорения $\left(F_{j}\right) ; V$ - скорость транспортного средства, $\kappa м / ч ; \eta_{\text {mяг }}, \eta_{\text {mорм }}$ - КПД тягового привода, учитывающая КПД двигателя и КПД преобразователя в режиме тяги и торможения соответственно; $I_{b}$ и $U_{b}$ - ток и напряжение в ячейке аккумулятора. 
Таблица 4. Параметры легкового автомобиля

Table 4. Parameters of a passenger car

\begin{tabular}{|l|c|c|}
\hline \multicolumn{1}{|c|}{ Параметр } & Размерность & Величина \\
\hline Масса ТС & $\kappa 2$ & 1690 \\
\hline Коэффициент сопротивления воздуха & --- & 0,4 \\
\hline Площадь передней части & $\mathcal{M}^{2}$ & 1,2258 \\
\hline Плотность воздуха & $\kappa 2 / \mathrm{M}^{3}$ & 0,96 \\
\hline КПД трансмиссии $\eta_{\text {т }}$ & --- & $0,0076+0,000056 \cdot V$ \\
\hline Коэффициент сопротивления качению [8] & --- & 375 \\
\hline Выходное напряжение аккумулятора & $\mathrm{B}$ & \\
\hline
\end{tabular}

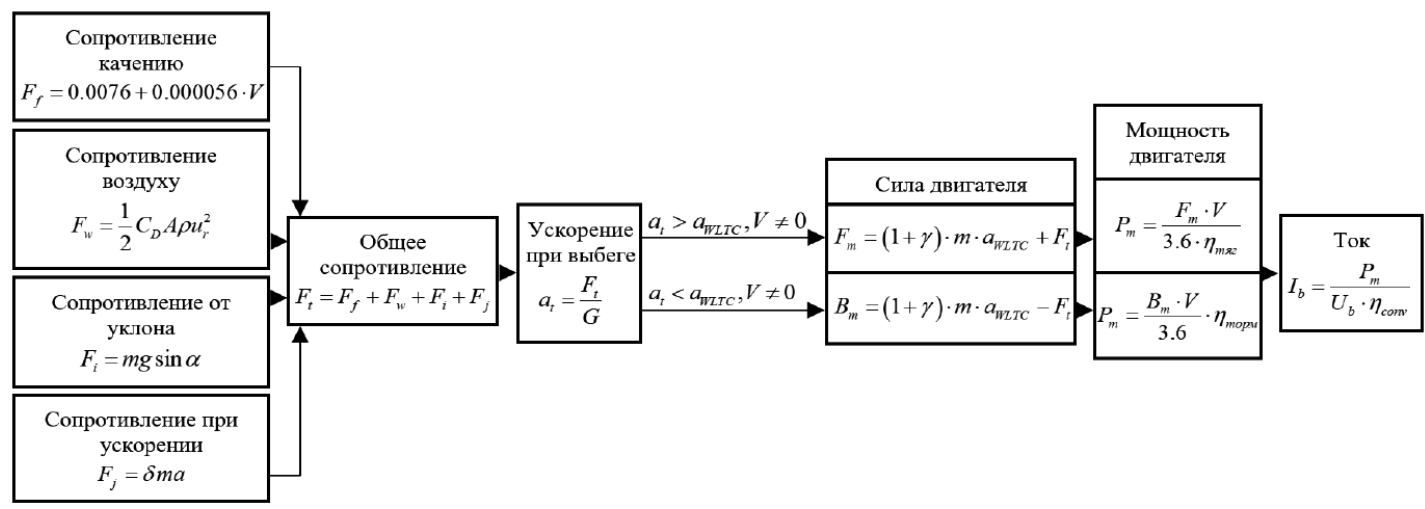

Рис. 5. Блок-схема расчета тока разгрузки в аккумуляторе

Fig. 5. Calculation of the load current in the battery algorithm

Как показано в методе, реализуемая сила двигателя зависит от текущего режима движения. Он определяется на основе сравнения ускорения в цикле и ускорения замедления от основного сопротивления движению.

В соответствии с моделью выходная мощность двигателя электропривода в режиме тяги и торможения определяется уравнениями

$$
\begin{aligned}
& P_{\text {тяг }}=\frac{F_{m} \cdot V}{3,6 \cdot \eta_{\text {тяг }}}, \mathrm{Bm}, \\
& P_{\text {торм }}=\frac{B_{m} \cdot V}{3,6} \cdot \eta_{\text {торм }}, \mathrm{Bm} .
\end{aligned}
$$

Зная, что выходное напряжение на аккумуляторе варьируется (320..410), принимаем усредненное значение в $U_{b}=375 B$, тогда ток в аккумуляторе

$$
I_{b}=\frac{P_{m}}{U_{b} \cdot \eta_{c o n v}}, A \text {. }
$$


Аккумулятор состоит из 48 неразборных модулей, соединенных последовательно. В неразборном модуле 4 (6 в случае АБ $62 \kappa B m \cdot 4)$ ячейки, которые соединены в $n_{p}=2$ (3 в случае АБ $62 \kappa B m \cdot u)$, параллельные цепочки.

Следовательно, ток в ячейке

$$
I_{s b}=\frac{I_{b}}{n_{p}} .
$$

Для удобства представления перегрузки введем соотношение

$$
I_{\text {отн }}=\frac{I_{s b}}{I_{1 C}} .
$$

Полученные диаграммы относительных токов для батареи Nissan Leaf энергоемкости 24 и $62 \kappa B m \cdot ч$ представлены на рис. 6.

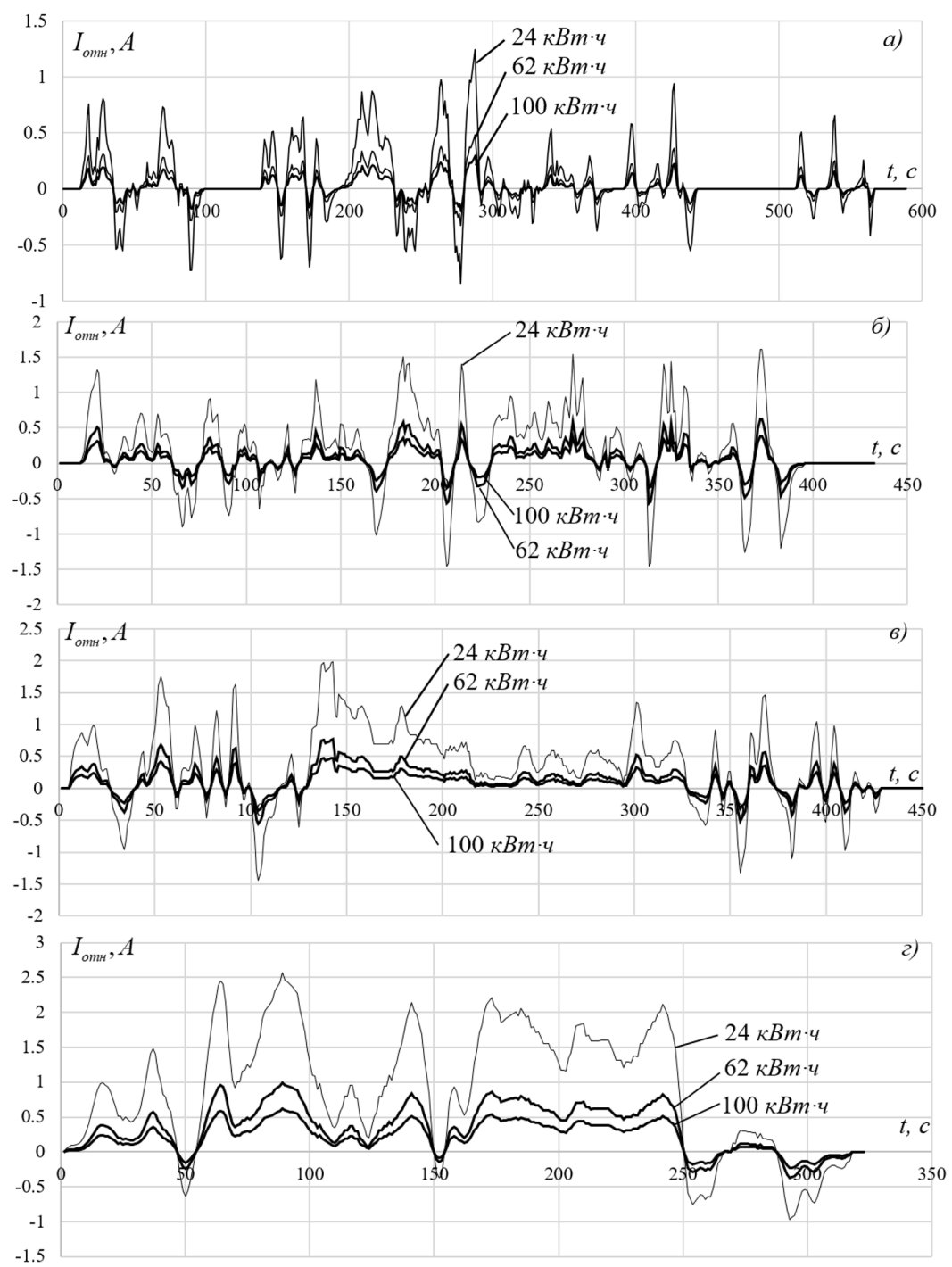

Рис. 6. Диаграммы относительных токов одиночной ячейки АБ: a - Low; б - Medium; в - High; г-E. High Fig. 6. Diagrams of relative currents of a single cell: a - Low; 6 -Medium; в-High; г - E. High 


\section{3. Сравнение результатов для АБ различной энергоемкости}

На рис. 7 и 8 представлены гистограммы распределения относительных токов $\left(I_{\text {отн }}\right)$ одиночной ячейки в режиме тяги и торможения для различной энергоемкости БН, значения имеют дискретность в одну секунду, что соответствует одному событию.

Оптимальными для АБ являются токи менее $1 \mathrm{C}$ при нагрузке и менее 0,5С при заряде $[9,10]$. Получено, что в первых трех режимах управления ЭТС с АБ энергоемкостью $62 \kappa B m \cdot ч$
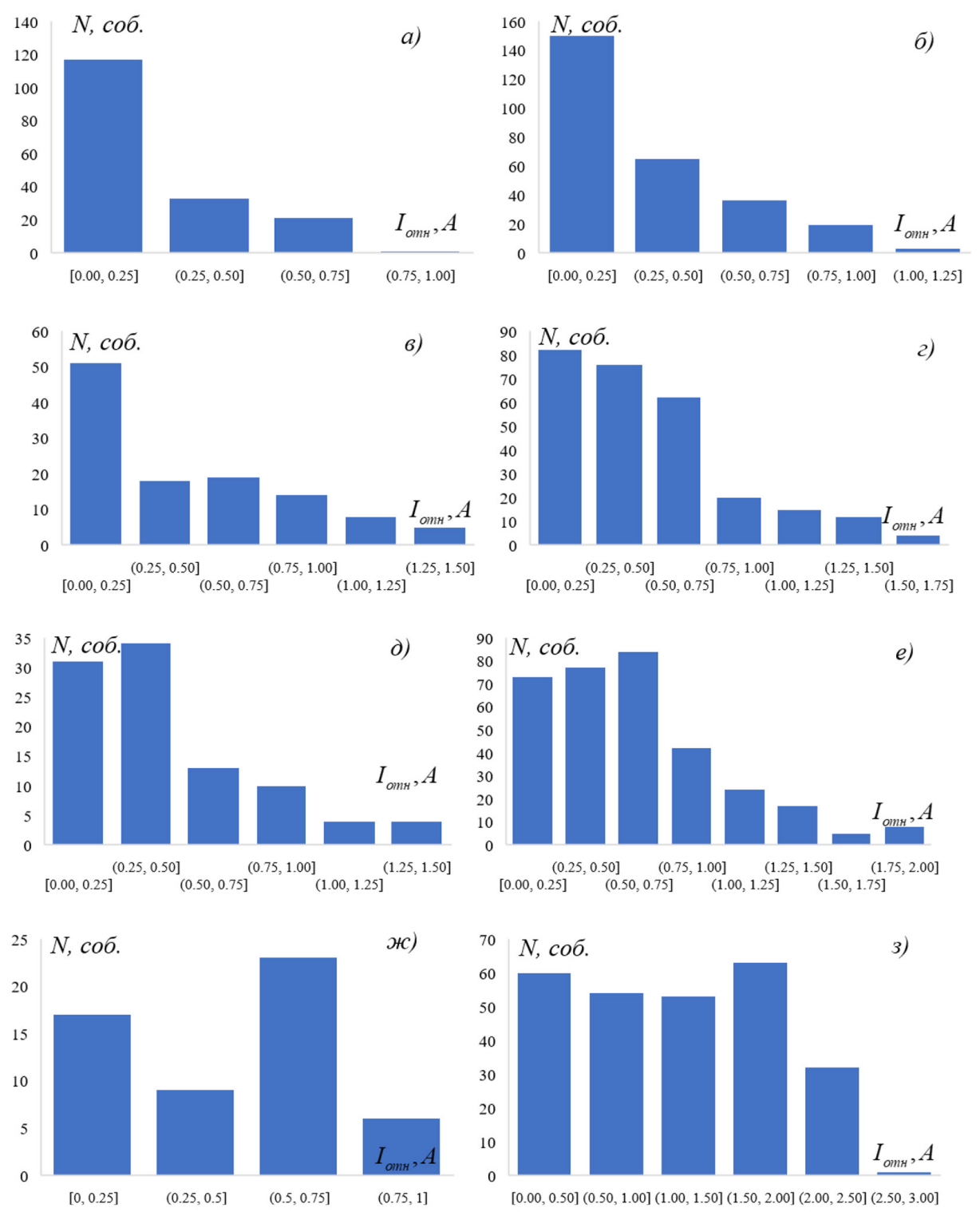

Рис. 7. Гистограммы относительных токов, АБ 24 кBm·ч: a - Low, торможение; 6 - Low, тяга; в - Medium, торможение; г-Medium, тяга; д - High, торможение; e - High, тяга; ж-E. High, торможение; 3 - E. High, тяга

Fig. 7. Relative currents histograms, ESU $24 \mathrm{~kW} \cdot \mathrm{h}$ : a - Low, braking; 6 - Low, thrust; в - Medium, braking; гMedium, thrust; д - High, braking; e - High, thrust; ж - E. High, braking; 3 - E. High, thrust 

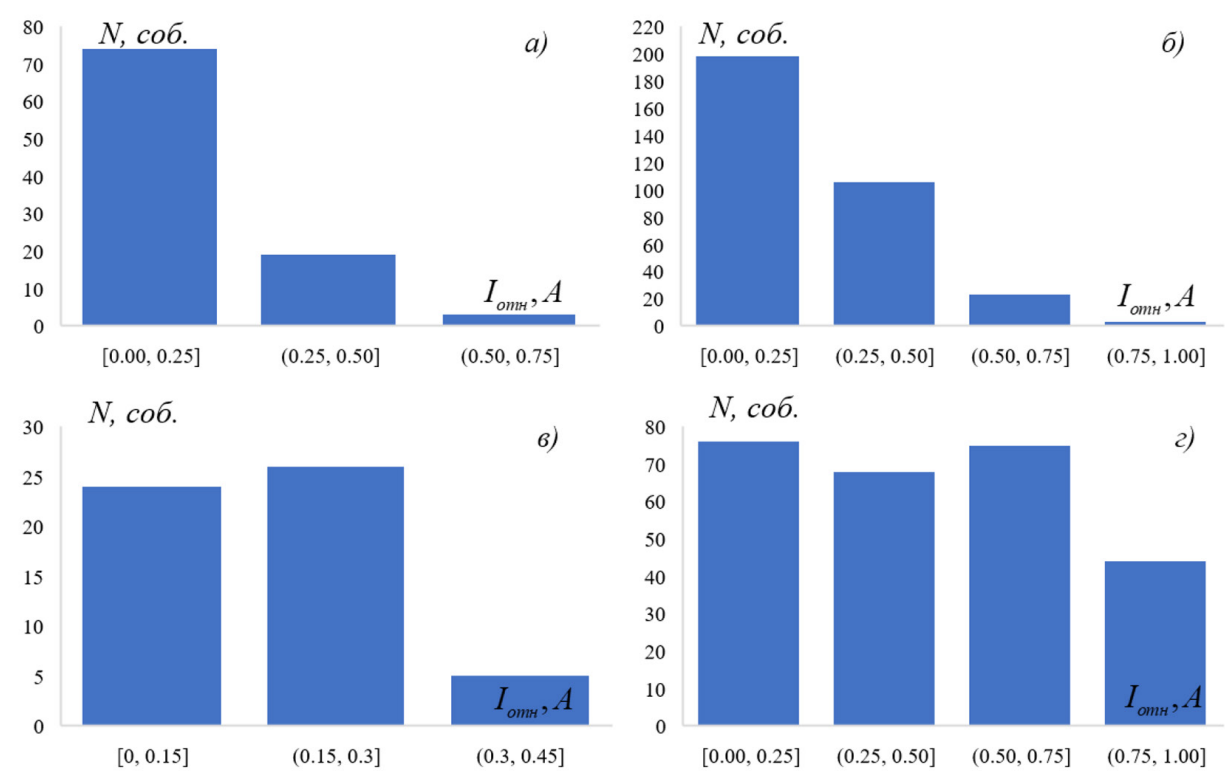

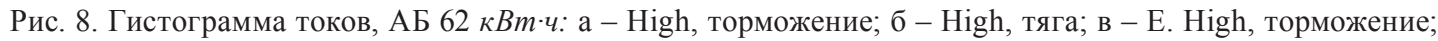
$\Gamma-$ E. High, тяга

Fig. 8. Relative currents histograms, ESU 62 kWh: a - High, braking; 6 - High, thrust; в - E. High, braking; $\Gamma-$ E. High, thrust

токи заряда и разряда лежат в оптимальном диапазоне. Поэтому для анализа приведены диаграммы при режимах управления High и Extra High (рис. 8).

Из анализа гистограмм (рис. 7, 8) следует, что в городском режиме движения большую часть времени потребляются малые токи (без превышения значений в 1 В в режиме тяги и 0,5С в режиме торможения). Однако их значения достаточны для обеспечения необходимой динамики разгона и торможения в плотном транспортном потоке, а также для подрегулирования скорости ЭТС. С увеличением максимальной скорости разгона при движении в городской среде без пробок с более длительным нахождением ЭТС в условиях ненулевой скорости пропорционально увеличивается среднее и максимальное значение токов. Однако пик гистограмм тока тяги и торможения в городском режиме составляет до 0,25C.

При движении в загородном режиме происходит увеличение среднего значения токов тяги и рекуперации и рост максимального значения перегрузки. Так, максимальные токи тяги в High и E. High - режимах составляют 2C и 3С соответственно, а токи торможения - $1 \mathrm{C}$ и 1,5C. Изменение максимального тока рекуперации в более тяжелом режиме движения объясняется тем, что при движении с высокой скоростью основной тормозной силой является сопротивление воздушной среды. Поэтому при одинаковых динамических параметрах замедления в режиме E. High требуется меньшая тормозная сила. Следует отметить, что в загородных режимах пик гистограмм приходится на диапазон 0,5С и выше. Основные количественные соотношения представлены в табл. 5, качественная оценка приведена на рис. 9 и 10.

В случае увеличения энергоемкости БН в данном типе ЭТС до $100 \kappa B m \cdot ч$ на протяжении всего цикла WLTC ток в ячейке не превысит 1C для режима тяги и 0,5C для режима торможения, то есть фактически перегрузка по току будет исключена. 
Таблица 5. Доля токов тяги и торможения в различных режимах управления, выраженная в процентах по времени движения

Tadle 5. Fraction of traction and braking currents in various control modes, expressed as a percentage by movement time

\begin{tabular}{|c|c|c|c|c|c|c|c|}
\hline \multicolumn{2}{|c|}{} & \multicolumn{3}{|c|}{ Режим тяги } & \multicolumn{3}{c|}{ Режим торможения } \\
\cline { 3 - 9 } & $(0 ; \mathrm{C} 1]$ & $(\mathrm{C} 1 ; \mathrm{C} 2]$ & $(\mathrm{C} 2 ; \mathrm{C} 3]$ & $(0 ; \mathrm{C} 0,5]$ & $(\mathrm{C} 0,5 ; \mathrm{C} 1]$ & $(\mathrm{C} 1 ; \mathrm{C} 1,5]$ \\
\hline \multirow{4}{*}{$\begin{array}{c}\text { АБ } 24 \\
\kappa B m \cdot 4\end{array}$} & Low & 100 & - & - & 89 & 11 & - \\
\cline { 2 - 9 } & Medium & 87,4 & 12,6 & - & 61,5 & 27,5 & 11 \\
\cline { 2 - 9 } & High & 82,5 & 18,6 & 0,9 & 67,4 & 23,6 & 9 \\
\hline \multirow{3}{*}{$\begin{array}{c}\text { АБ } 62 \\
\kappa B m \cdot \varphi\end{array}$} & E. High & 39,2 & 42,6 & 18,2 & 46,2 & 53,8 & - \\
\cline { 2 - 9 } & Low & 100 & - & - & 100 & - & - \\
\cline { 2 - 9 } & Medium & 100 & - & - & 96,5 & 3,5 & - \\
\cline { 2 - 9 } & E. High & 100 & - & - & 100 & - & - \\
\hline
\end{tabular}

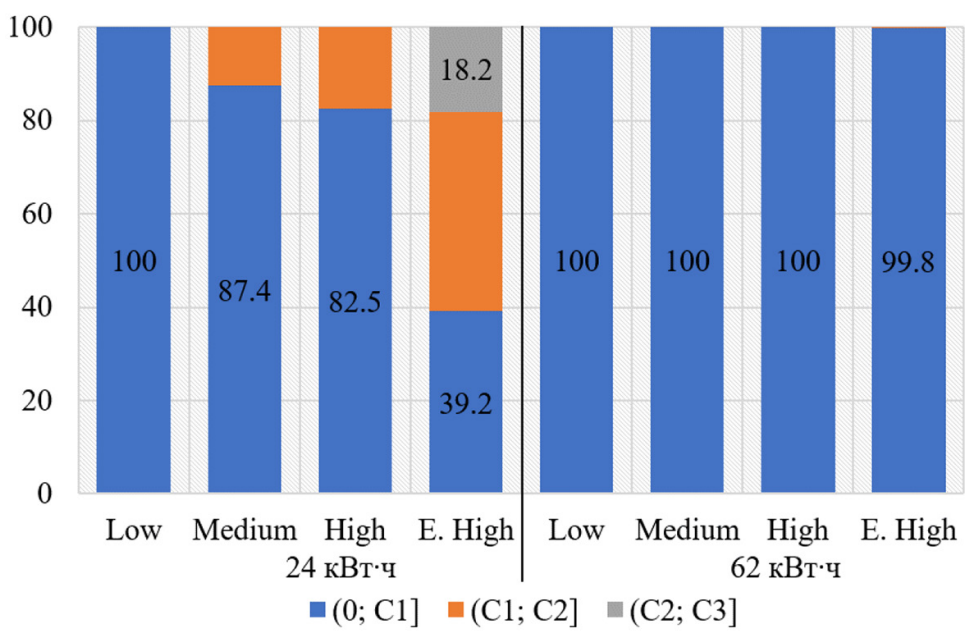

Рис. 9. Доля токов тяги в различных режимах управления

Fig. 9. Fraction of traction currents in different phases

Сопоставляя данные табл. 5, установили, что при добавлении параллельной ветви аккумуляторных ячеек максимальные токи нагрузки в режимах тяги и торможения значительно снижаются и составляют 1C и менее во всех режимах движения согласно циклу WLTC. Из этого можно предположить, что срок службы такого АБ возрастет ввиду меньших токовых нагрузок, также возрастет возможная перегрузка и, как следствие, возможно повышение динамических показателей ЭТС. Параллельное соединение ячеек уменьшает общее сопротивление БН. В совокупности с малыми токами это позволяет создать БН с более компактным расположением ячеек, а снижение плотности тока будет приводить к упрощению создаваемых систем теплоотвода с возможностью более компактного расположения ячеек. 


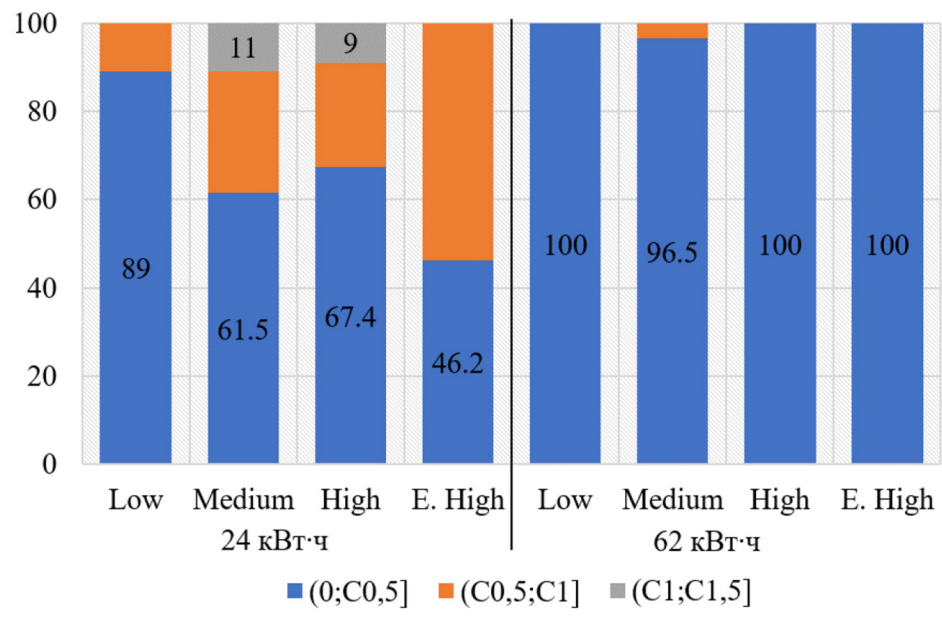

Рис. 10. Доля токов торможения в различных режимах управления

Fig. 10. Fraction of braking currents in different control modes

\section{4. Выводы}

Качественное отличие в режимах работы накопителей энергии в составе тягового привода транспортных средств определяется двумя факторами: быстрым непродолжительным темпом наброса нагрузки при интенсивном разгоне, в несколько раз превышающим номинальные показатели, и частым реверсивным энергообменом с короткими режимами подзаряда АБ при рекуперативном торможении.

В работе показано, что существует тенденция, направленная на увеличение энергоемкости устанавливаемых АБ. При этом, как следствие, снижается перегрузка отдельной ячейки как в режиме тяги, так и в режиме торможения. Поэтому в будущем возможно ожидать, что основным фактором старения АБ будет не токовая перегрузка, а ее реверсивный характер. Рост энергоемкости БН влечет за собой увеличение возможно допустимой величины тока, что означает повышение динамики разгона автомобиля, т.е. уменьшение времени перегрузки, а добавление параллельных ячеек снижает общее сопротивление АБ. В совокупности данные факторы позволяют снизить тепловыделение с одиночной ячейки и уменьшить габариты АБ.

\section{Благодарности / Acknowledgments}

Исследование выполнено при финансовой поддержке РФФИ и ГФЕН Китая в рамках научного проекта № 20-58-53055 «Исследование влияния форсированных и тяжелых циклических режимов заряда и разряда на физико-химические характеристики функциональных материалов и ресурса литиевых аккумуляторов».

The study was carried out with the financial support of the Russian Foundation for Basic Research and the State Foundation for Basic Research of China in the framework of the scientific project No. 20-58-53055 "Investigation of the effect of forced and heavy cyclic charge and discharge modes on the physicochemical characteristics of functional materials and the resource of lithium batteries." 


\section{Список литературы / References}

[1] Bloomberg New Energy Finance 2019 [Электронный ресурс] - Режим доступа: https:// bnef.turtl.co/story/neo2019/page/1?teaser=true - Заглавие с экрана. [Bloomberg New Energy Finance 2019 [Electronic resource] - Access: https://bnef.turtl.co/story/neo2019/page/1?teaser=true

[2] Shtang A.A., Yaroslavtsev M.V., Dedov S.I., Xiaogang W. Comparison of energy consumption of different types of passenger public transport in russian operational conditions, 20 International conference of young specialists on micro/nanotechnologies and electron devices, EDM 2019, Altai Republic, Erlagol, 2019, 705-710

[3] Groot J. State-of-Health Estimation of Li-ion Batteries: Ageing Models, Doctoral Thesis at the Graduate School in Energy and Environment, Chalmers University of Technology, 2014.

[4] Оспанбеков Б.К. Оптимизация ресурсоопределяющих эксплуатационных режимов тяговых аккумуляторных батарей электромобилей, дис. ... канд. тех. наук. Москва, 2017, 170 c. [Ospanbekov B.K. Optimization of resource-determining operating modes of electric vehicles traction batteries, dis. ... Cand. of tech. Sci. Moscow, 2017, 170 p. (In Russian)]

[5] Pankaj Arora, Ralph E. White, Marc Doyle, Capacity Fade Mechanisms and Side Reactions in Lithium-Ion Batteries, Journal of The Electrochemical Society, 1998, 145, 10

[6] Daniel-Ioan Stroe, Søren Knudsen Kær, Egoitz Martinez-Laserna, Maciej Swierczynski, Accelerated aging of Lithium-ion batteries based on electric vehicle mission profile, 2017 IEEE Energy Conversion Congress and Exposition (ECCE), 2017

[7] Samveg Saxena, Caroline Le Floch, Jason MacDonald, Scott Moura, Quantifying EV battery end-of-life through analysis of travel needs with vehicle powertrain models, Journal of Power Sources, 2015, 282, 265-276

[8] Gillespie Thomas D., Fundamentals of Vehicle Dynamics. Society of Automotive Engineers, Inc, 1992. 470 p.

[9] Zhengyu Chu, Xuning Feng, Minggao Ouyang, Zuofu Wang, Languang Lu, Jianqiu Li, Xuebing Han, Optimal charge current of lithium ion battery, Energy Procedia, 2017, 142, 1867-1873

[10] Medvedev O.S., Wang Q., Popovich A.A. \& Novikov P.A. Comparison of conductive additives for high-power applications of Li-ion batteries, Ionics, 2020, 26, 4277-4286

[11] Yaroslavtsev M.V., Shtang A.A, Dedov S.I. Automated calculation of economic feasibility of using various types of passenger public transport in Russian conditions, Journal of Physics Conference Series, 2019, 1333, 7

[12] Takei K., Kumai K., Kobayashi Y., Miyashito H., Terada N., Iwahori T., Tanaka T. Cycle life estimation of lithium secondary battery by extrapolation method and accelerated aging test, $J$. Power Sources, 2001, 97-98, 697-701

[13] Madeleine Ecker, Calendar and cycle life study of Li(NiMnCo)O2-based 18650 lithium ion batteries, Journal of Power Sources, 2014, 248, 839-851

[14] Tobishima S., Yamaki J., Hirai T. Safety and capacity retention of lithium ion cells after long periods of storage, Journal of Applied Electrochemistry, 2000, 30, 405-410

[15] Waldmann T., Kasper M., Fleischhammer M., Wohlfahrt M. Temperature dependent ageing mechanisms in Lithium - ion batteries - A Post - Mortem study, Journal of Power Sources, Elsevier, 2014, 363, 129-135 
[16] Сяоган У, Сюефэн Ли, Щуров Н.И., Штанг А.А., Ярославцев М.В., Дедов С. Определение уровня заряда литий-ионного аккумулятора на основе алгоритма расширенного фильтра Калмана, Журн. Сиб. федер. ун-та. Техника и технологии, 2020, 13(4), 420-437 [Wu Xiaogang, Xuefeng Li, Shurov N.I., Shtang A.A., Yaroslavtcev M.V., State-of-Charge Estimation of Lithium-Ion Battery Based on Extended Kalman Filter Algorithm, J. Sib. Fed. Univ. Eng. technol., 2020, 13(4), 420-437 (In Russian)].

[17] Рожко Д.Я. Альтернативные и переходные источники энергии для городского транспорта, Журн. Сиб. федер. ун-та. Техника и технологии, 2020, 13 (5), 586-596 [Rozhko D.Ya. Alternative and Transitional Energy Sources for Urban Transport, J. Sib. Fed. Univ. Eng. technol., 2020, 13 (5), 586-596 (In Russian)] 